\title{
Influence of Oxygen content on the electrochemical behavior of $\operatorname{Ta}_{1-\mathrm{x}} \mathrm{O}_{\mathrm{x}}$ coatings
}

\author{
C.F. Almeida Alves ${ }^{a, *}$, S.V. Calderón ${ }^{a, b}$, D. Dias ${ }^{a}$, S. Carvalho ${ }^{a, b}$ \\ a GRF-CFUM, Physics Department, University of Minho, Campus of Azurem, 4800-058 Guimarães, Portugal \\ b SEG-CEMUC, Mechanical Engineering Department, University of Coimbra, 3030-788 Coimbra, Portugal
}

\section{A R T I C L E I N F O}

\section{Article history:}

Received 15 December 2015

Received in revised form 27 May 2016

Accepted 28 May 2016

Available online 28 May 2016

\section{Keywords:}

$\mathrm{Ta}_{1-\mathrm{x}} \mathrm{O}_{\mathrm{x}}$ coatings

dental implants

corrosion performance

EIS

\begin{abstract}
A B S T R A C T
In this study, $\mathrm{Ta}_{1-\mathrm{x}} \mathrm{O}_{\mathrm{x}}$ coatings were deposited by reactive magnetron sputtering aiming at the enhancement of the electrochemical stability stainless steel $316 \mathrm{~L}$. The coatings were produced using variable oxygen content in order to determine its influence on the films morphological features and corrosion resistance. Structural and morphological characteristics were correlated with the corrosion behavior in artificial saliva. Potentiodynamic and electrochemical impedance spectroscopy tests were complemented with X-ray photoelectron spectroscopy to determine the electrochemical behavior of the coatings. The results reveal a more protective behavior of the coatings as the oxygen amount increases in the films, as well as pitting inhibition in the coated stainless steel, independently of the film composition. A synergetic effect between $\mathrm{Ta}_{2} \mathrm{O}_{5}$ and phosphate-based passive layers is suggested as the protective mechanisms of the coatings; while the more active electrochemical behavior of low oxygen content films is evidenced as a consequence of the metallic tantalum on the surface with a more open morphology and larger density of defects on the surface.
\end{abstract}

(c) 2016 Published by Elsevier Ltd.

\section{Introduction}

Nowadays, dental implants are usually fabricated using titanium (Ti) based materials due to its biocompatibility and strong corrosion resistance [1]. Ti6Al4V is the most common alloy for this application due to its higher corrosion resistance [2,3]. However, the low capacity to form a strong chemical bond with living tissue, known as bioactivity, is a significant limitation for Tibased materials $[4,5]$. In fact, the number of dental implants failures associated to the healing process (osseointegration) is around $47 \%$ before artificial crown implantation and 53\% during the first year of use [6]. Currently, tantalum (Ta) is proposed as an alternative to replace $\mathrm{Ti}$. Ta is a bioactive element presenting interesting wettability and surface free energy which promotes osseointegration and good corrosion resistance [7-10]. The superior surface free energy of tantalum oxides stimulates the regeneration process in living tissues, and thus, increases the

\footnotetext{
* Corresponding author at: Universidade do Minho, Escola de Ciências, Departamento de Física, Campus de Azurém, 4800-058 Guimarães, Portugal. Tel.: +351 253 510467; fax: +351253510461.

E-mail addresses: cristiana.alves@fisica.uminho.pt, http://smf-materials.weebly.com/ (C.F. Almeida Alves).
}

efficiency of osseointegration [10-13], besides enhancing corrosion resistance due to its high chemical stability [14-16]. However, Ta presents higher prices and density comparatively with other metals [15,17]. Hence, the objective of this work is to coat stainless steel 316L (SS 316L) with $\mathrm{Ta}_{1-\mathrm{x}} \mathrm{O}_{\mathrm{x}}$ films to combine the enhanced bioactivity of Ta-based materials [18] with the low cost of SS 316L and evaluate the system corrosion resistance in artificial saliva.

The degradation of metallic dental implants is a common process caused by the physiological environment that surrounds the implant. Thus, additionally to an excellent osseointegration shown by the developed bioactive surfaces, it is mandatory to further evaluate their corrosion properties in order to obtain an appropriate coating performance.

Previous works studying the corrosion of Ti-based dental implant materials reported that the stability of the $\mathrm{TiO}_{2}$ protective passive layer (Me-O) is $\mathrm{pH}$ dependent and can degrade in the oral environment due to the presence of corrosive substances on saliva $[19,20]$. As mentioned before, Ta-based materials can replace Ti dental implants. Consequently, it is important to note that only few studies report the corrosion performance of Ta-based materials and are out of the scope of dental implant application. Mostly, the studies focus on Ta corrosion behavior influenced by crystalline phases [21,22] or surface roughness [23] in acid environments (i.e. $\mathrm{H}_{2} \mathrm{SO}_{4}$ ), or on the influence of different Ta deposition methods on 
the corrosion performance in saline environments $(\mathrm{NaCl})$, testing steel corrosion protection approaches [24]. For instance, it has been reported that coatings with $\alpha$-Ta or $\beta$-Ta phases showed protective behavior to steel substrates being dependent on the presence of defects such as pinholes or porosity. The corrosion processes is controlled by the steel dissolution through the open pores. Still, $\beta$-Ta structure is more susceptible to suffer corrosion due to its brittle nature [21,22]. Additionally, it was found that the corrosion protection was maintained even using substrates with different roughness [23]. On the other hands, the electrochemical performance for tantalum oxides has shown to be dependent on the oxide morphology/density, revealing a lower coating breakdown potential and faster pit growth in highly porous $\mathrm{Ta}_{2} \mathrm{O}_{5}$. Furthermore, some studies are focused on $\mathrm{Ta}_{2} \mathrm{O}_{5}$ corrosion performance for bio-applications, due to the high biocompatibility and bioactivity, however in Simulated Body Fluid (SBF) environment $[16,25]$, which present a more neutral character compared to simulated saliva. Besides the improvement of corrosion resistance of Ti by Ta-based coating, denser $\mathrm{Ta}_{2} \mathrm{O}_{5}$ coating improves corrosion resistance in biological environments [16,25].

As a result, this work is focused on the electrochemical assessment in artificial saliva of Ta and tantalum oxide films produced by DC reactive magnetron sputtering and the determination of the structural and morphological effect on the electrochemical characteristics.

\section{Experimental Details}

\subsection{Coatings deposition}

Ta-based films were deposited onto polished stainless steel 316L (SS 316L) $\left(20 \times 20 \mathrm{~mm}^{2}\right)$ and single crystalline silicon (100) $\left(1 \times 1 \mathrm{~mm}^{2}\right)$ substrates by reactive DC magnetron sputtering using a high-purity Ta target $(99.6 \% \mathrm{Ta})\left(200 \times 100 \mathrm{~mm}^{2}\right)$. The SS $316 \mathrm{~L}$ substrates were grinded using emery paper from 600 to 2400 grit and then mirror polished with a diamond solution, attaining a surface roughness $<3 \mathrm{~nm}$. All the substrates were ultrasonically cleaned using distilled water, ethanol and acetone for $10 \mathrm{~min}$ in each solvent.

The substrates were located at $70 \mathrm{~mm}$ in front of the target and the rotation speed and deposition temperature were kept constant at $7 \mathrm{rpm}$ and $\sim 200^{\circ} \mathrm{C}$, respectively. Previous to each deposition, the substrates were sputter-etched to remove remaining impurities and surface oxides on the target and substrate surface, improving film adhesion. To further enhance the coatings adhesion a Ta interlayer was deposited, with approximately $200 \mathrm{~nm}$. The interlayer deposition was carried out with a current density of $10 \mathrm{~mA} \mathrm{~cm}^{-2}$ in $\mathrm{Ar}$ atmosphere $(0.6 \mathrm{~Pa})$ at constant bias voltage $(-75 \mathrm{~V})$. The film depositions were carried out in $\mathrm{Ar}+\mathrm{O}_{2}$ atmosphere with a constant bias voltage of $-75 \mathrm{~V}$. The current density applied to the Ta target was varied from 10 to $5 \mathrm{~mA} \mathrm{~cm}^{-2}$ in order to achieve stoichiometric tantalum oxide. Ar flow was kept constant while the $\mathrm{O}_{2}$ flow was adjusted, as depicted in Table 1 . The base pressure was $6 \times 10^{-4} \mathrm{~Pa}$ and the discharge pressure ranged from 0.6 to $0.7 \mathrm{~Pa}$ depending on the gas flow.

\subsection{Coatings characterization}

The coating chemical composition was determined by Cameca SX50 electron probe microanalysis (EPMA) equipment, operating at $10 \mathrm{kV}$ and $40 \mathrm{nA}$. Scanning electron microscopy (SEM) was used to observe the surface and cross-sectional morphology of the films and measure the film thickness employing a NanoSEM - FEI Nova 200 (SEM) operating at $5 \mathrm{keV}$ and a LEICA S360 microscope, operating at $15 \mathrm{kV}$ in secondary electron mode. XPS analysis was performed using a Kratos AXIS Ultra HSA, with VISION software for data acquisition and CASAXPS software for data analysis. The analysis was carried out with a monochromatic $\mathrm{Al} \mathrm{K \alpha} \mathrm{X}$-ray source $(1486.7 \mathrm{eV})$, operating at $15 \mathrm{kV}(150 \mathrm{~W})$, in FAT mode (Fixed Analyser Transmission), with a pass energy of $40 \mathrm{eV}$ for regions ROI and $80 \mathrm{eV}$ for survey. Data acquisition was performed with a pressure lower than $1 \times 10^{-6} \mathrm{~Pa}$, and a charge neutralisation system was used. The effect of the electric charge was corrected by the reference of the carbon peak $(285 \mathrm{eV})$.

Optical micrographs were obtained to analyze the size, area and distribution of surface defects using ImageJ software and a subsequently descriptive statistical analysis was performed. EPMA, SEM and XRD analysis were performed in coatings deposited onto Si substrates, while XPS analysis and optical microscopy were performed on coatings deposited onto SS 316L.

\subsection{Electrochemical experiments}

The corrosion performance was assessed by open circuit potential (OCP), electrochemical impedance spectroscopy (EIS) and anodic potentiodynamic polarization experiments. The apparatus for electrochemical measurement consisted of a Gamry REF600 potenciostat controlled by EIS300 and DC105 software. Electrochemical experiments were carried out with a standard three-electrode cell. A saturated calomel electrode (SCE) was used as the reference electrode with a platinum counter electrode and the SS 316L coated with Ta-based film as the working electrode, with an exposed area of $0.44 \mathrm{~cm}^{2}$. The experiments were performed on CP Ti grade 2 (Gr2) (ASTM: F67) as a commercial surface control, on SS 316L as surface control and on $\mathrm{Ta}_{1-\mathrm{x}} \mathrm{O}_{\mathrm{x}}$ coatings as a developed surfaces. Each sample was immersed into a volume of $200 \mathrm{ml}$ of Fusayama artificial saliva $(0.4 \mathrm{wt} . \% \mathrm{NaCl}$; 0.4 wt.\% KCl; 0.795 wt.\% $\quad \mathrm{CaCl}_{2} \cdot 2 \mathrm{H}_{2} \mathrm{O} ; 0.005$ wt.\% $\quad \mathrm{Na}_{2} \mathrm{~S} \cdot 9 \mathrm{H}_{2} \mathrm{O}$; 0.69 wt.\% $\mathrm{NaH}_{2} \mathrm{PO}_{4} \cdot 2 \mathrm{H}_{2} \mathrm{O}$; and 1 wt.\% Urea) with stabilized $\mathrm{pH}$ at 5.5 in equilibrium with air. The tests were performed at room temperature, under static conditions. Three measurements were performed for each sample to statistically validate the results. OCP and EIS experiments were carried out as a function of the immersion time after 2, 24 hours and 7 days. Before each impedance experiment, a stable OCP potential was achieved during 1 hour for the first measurement and $30 \mathrm{~min}$ for the

Table 1

Chemical composition, deposition parameters, thickness and deposition rate of the deposited samples.

\begin{tabular}{|c|c|c|c|c|c|c|}
\hline \multirow[t]{2}{*}{ Sample } & \multicolumn{2}{|c|}{$\begin{array}{l}\text { Chemical composition } \\
\text { (at.\%) }\end{array}$} & \multirow[t]{2}{*}{$\mathrm{O}_{2}$ Flow $(\mathrm{sccm})$} & \multirow[t]{2}{*}{ Currenty density $\left(\mathrm{mAcm}^{-2}\right)$} & \multirow[t]{2}{*}{ Thickness $(\mu \mathrm{m})$} & \multirow[t]{2}{*}{ Deposition rate $\left(\mu \mathrm{m} \mathrm{h}^{-1}\right)$} \\
\hline & $\mathrm{Ta}$ & $\mathrm{O}$ & & & & \\
\hline T06 & $95 \pm 0.3$ & $5 \pm 0.3$ & 0 & 10 & 4.5 & 2.3 \\
\hline T01 & $89 \pm 0.6$ & $11 \pm 0.6$ & 2 & 10 & 4.2 & 2.1 \\
\hline TO5 & $57 \pm 0.2$ & $43 \pm 0.2$ & 10 & 10 & 5.5 & 2.8 \\
\hline TO6 & $30 \pm 0.4$ & $70 \pm 0.4$ & 13 & 5 & 3.8 & 1.9 \\
\hline
\end{tabular}



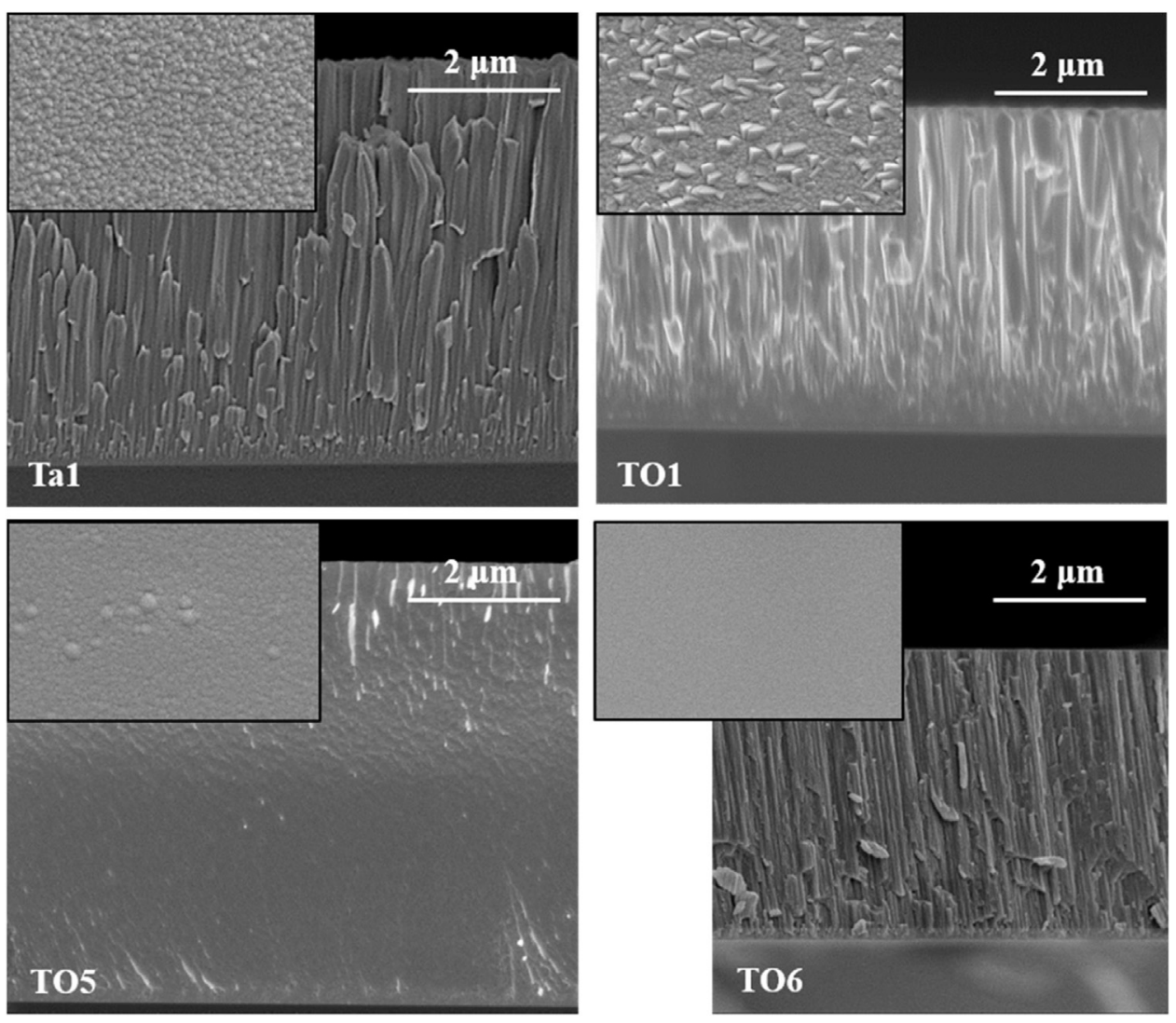

Fig. 1. SEM micrograph of $\mathrm{Ta}_{1-\mathrm{x}} \mathrm{O}_{\mathrm{x}}$ coatings as a function of oxygen content, deposited onto Si substrates. Each inset correspond to each coating surface.

following measurements. Thereafter, EIS experiments were carried out with a sinusoidal AC perturbation of $10 \mathrm{mV}$ (rms) amplitude around the open circuit potential applied to the electrode over the frequency range $0.001 \mathrm{~Hz}$ to $1 \mathrm{MHz}$. At the end of 7 days of immersion, potentiodynamic tests were performed using a scanning rate of $60 \mathrm{mV} / \mathrm{min}$ from $-0.3 \mathrm{~V}$ vs. OCP to $+1.2 \mathrm{~V}$ vs OCP. Potentiodynamic tests were also performed at 0 hours of immersion, allowing OCP primary stabilization, in order to study the influence of the immersion time on the electrochemical response.

\section{Results}

\subsection{Coatings chemical, structural and morphological characterization}

Table 1 shows the deposition conditions, chemical composition and some physical properties of the films. The chemical composition reveals a progressive increase of the oxygen content from 5 to 70 at. \% along with the decrease in tantalum content from 95 to 30 at. \%, following the $\mathrm{O}_{2}$ flow rate tendency. The oxygen content ( 5 at. $\%)$ present in Ta1 coating is related with some residual $\mathrm{O}_{2}$ in the chamber during the deposition. For a current density of $10 \mathrm{~mA}$ $\mathrm{cm}^{-2}$ with the increase of $\mathrm{O}_{2}$ flow rate, the amount of molecules inside the chamber increases, which leads to an increase of the deposition rate. When the current density change to $5 \mathrm{mAcm}^{-2}$ a significant decrease in the deposition rate is verified due to the reduction of the sputtering yield.

A complete structural analysis of the coatings was previously performed and can be found in previous publication [18]. Briefly, Xray diffraction analysis showed three fundamental behaviors: (i)
Ta1 coating revealed a crystalline body-centered cubic phase (bcc), characteristic $\alpha$-Ta phase; when the oxygen content increases to 11 at. \% (TO1), the coating maintains the crystallinity but changes from a bcc structure to a mixture of $\alpha$-Ta (bcc) and $\beta$-Ta (tetragonal) phases, due to the distortion of the $\alpha$-Ta phase by oxygen incorporation; (ii) for films with intermediate oxygen content (TO5) the coating became quasi-crystalline with a broader peak elucidating a mixture of phases, such as $\alpha-\mathrm{Ta}, \beta-\mathrm{Ta}_{2} \mathrm{Ta}_{2} \mathrm{O}, \mathrm{TaO}_{2}$ and/or $\mathrm{Ta}_{2} \mathrm{O}_{5}$; (iii) the coating with the highest oxygen content (TO6) is completely amorphous, without presence of any diffraction band.

SEM micrographs, showed in Fig. 1, demonstrate a typical columnar morphology for Ta1 and TO1. TO1 film shows sharp edges particles over the coating surface that, according to Zhou et al. [26], is related with the mixture of $\alpha$ and $\beta$ Ta phases, in agreement with XRD results. Denser coatings with featureless morphology are observed for higher oxygen content, which leads to a reduction in the size of the columns, showing a smooth surface (cf. Fig. 1 inset). This morphology confirms the results obtained by XRD analysis, which revealed a transition from nanocrystalline to amorphous coatings with increasing of oxygen content.

A more detailed study of the chemical, physical, structural and morphological properties of $\mathrm{Ta}_{1-\mathrm{x}} \mathrm{O}_{\mathrm{x}}$ coatings can be found in [18].

Fig. 2 shows the size distribution of the surface defects calculated from optical micrographs. The defects are usually identified as pin-holes and/or droplets associated to the sputtering process. The number of defects is evidently reduced both in the histogram and the surface micrographs when oxygen is incorporated (see Fig. 2) attributed to a morphology densification due to a more compact growth, as demonstrated by SEM surface images. 
a)

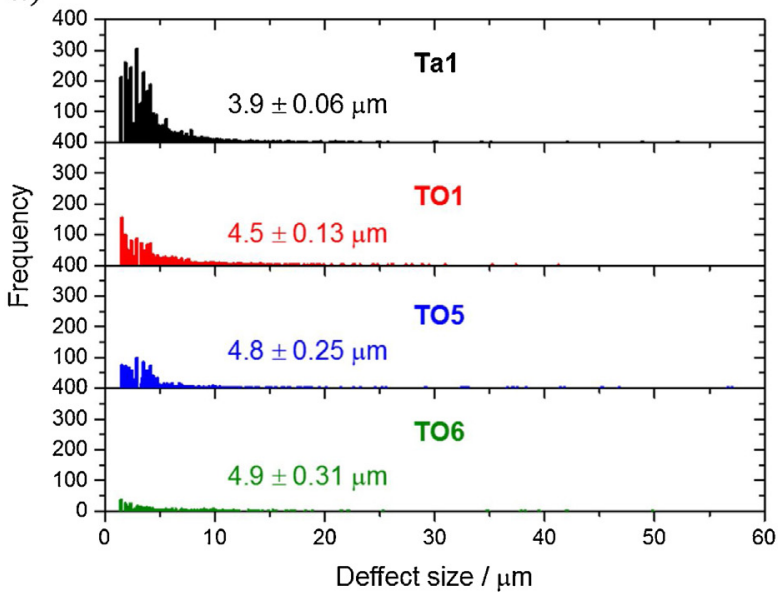

b)

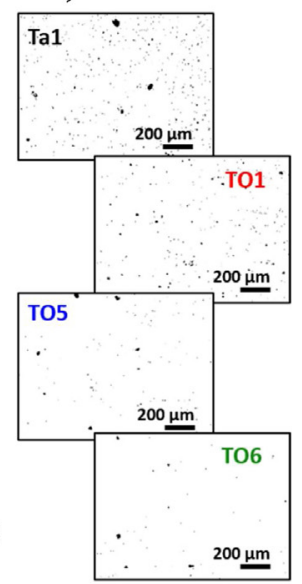

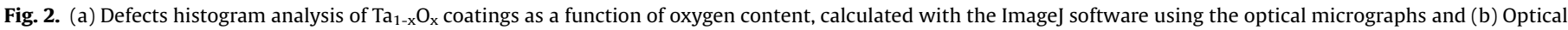
micrographs (8bits) of the as-deposited coatings on SS 316L.

\subsection{Electrochemical performance}

The electrochemical tests were performed in six samples, $\mathrm{CP} \mathrm{Ti}$ Gr2, SS 316L, Ta1, T01 TO5 and TO6; the first two serving as control samples, while the remaining four coatings correspond to the proposed bioactive surfaces.

The OCP evolution during 1 hour of immersion is plotted in Fig. 3a, showing a stable electrochemical cell after this period of time. The Ta1 coating showed an OCP value between -350 and $-400 \mathrm{mV} v s$. SCE. The TO1 and TO5 sub-stoichiometric coatings showed the lowest OCP values, even lower than Ta1 coating. In fact, these coatings reveal to have a mixture of $\alpha$-Ta, $\beta$-Ta and/or tantalum sub-stoichiometric oxides such as $\mathrm{Ta}_{2} \mathrm{O}, \mathrm{TaO}_{2}$ or $\mathrm{Ta}_{2} \mathrm{O}_{5}$ phases, while Ta1 coating evidences a pure $\alpha$-Ta phase. This suggests that the mixture of phases have an adverse effect in OCP of the samples, probably explained by a lower OCP of $\beta$-Ta phase, and hence, the mixed potential is reduced, causing an increase of the susceptibility for corrosion. TO6 coating, on the other hand, showed the highest OCP value around -100 and $-80 \mathrm{mV} v \mathrm{~s}$. SCE, due to the higher oxygen content that allow the formation of a stable stoichiometric oxide, which has better performance against corrosion.

Fig. 3b shows the OCP as a function of immersion time of $\mathrm{Ta}_{1-\mathrm{x}} \mathrm{O}_{\mathrm{x}}$ coatings in artificial saliva at room temperature after $2 \mathrm{~h}$, $24 \mathrm{~h}$ and 7 days. The values reveal that the Ta-based samples exhibit very stable OCP. The coatings with higher oxygen content show a slight overall increase of the OCP values after 7 days of immersion, which may indicate that dense oxide layers favor the increase of the energy barrier needed to suffer corrosion.

The potenciodynamic curves, 0 and 7 days after immersion, are plotted in Fig. 4. In all samples, pitting (metastable pitting) or localized corrosion was not observed, except for the bare SS 316L wherein the breakdown potential $\left(\mathrm{E}_{\mathrm{b}}\right)$ occurs at around $550 \mathrm{mV} v \mathrm{~s}$. SCE, revealing a protective behavior of the films for polarization induced corrosion of SS 316L, matching the performance of the $\mathrm{CP}$ Ti Gr2. Such localized corrosion protection is expected to be effective for compact morphologies (i.e. higher O content), where the penetration of the electrolyte can be more largely avoided, preventing the contact with the SS 316L. Thus, large defects or damage to the films must be avoided to maintain this protection.
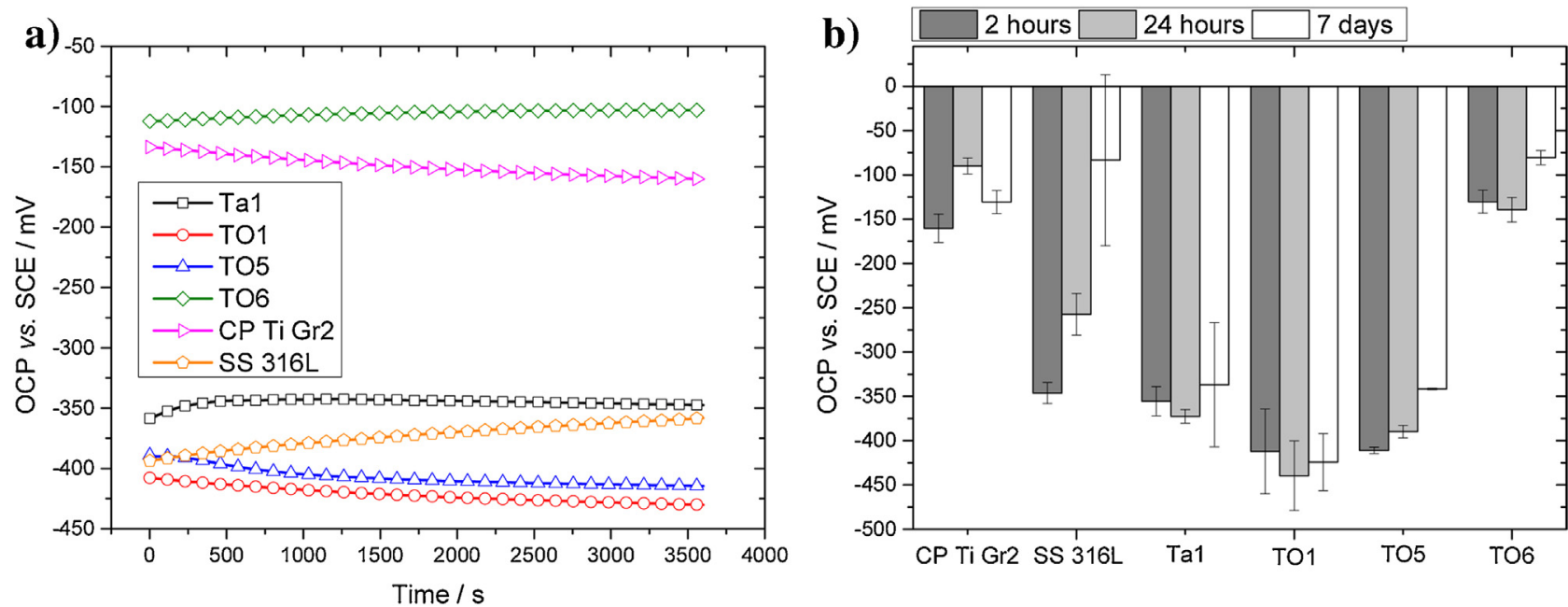

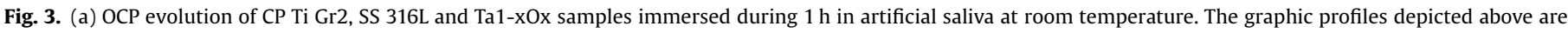

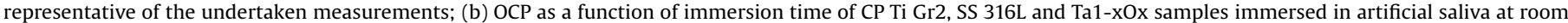
temperature. The results are an average calculated from three different samples. 

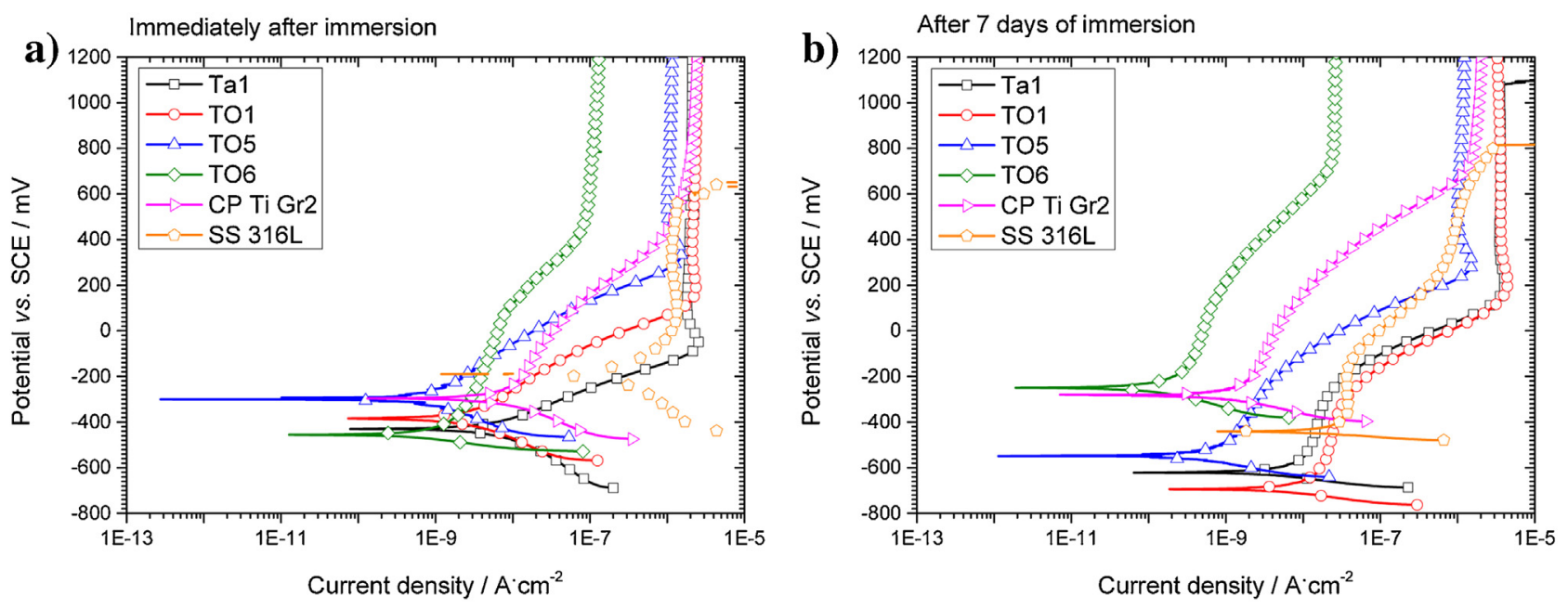

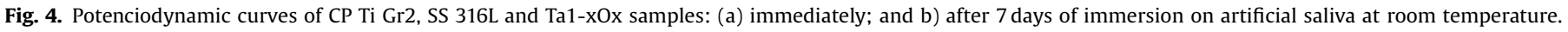

The potendiodynamic curves immediately after immersion also reveal that the coatings with higher oxygen content (TO5 and TO6) possess lower current density, indicating that corrosion occurs at slower rates, when compared to the other samples. These results are in agreement with the SEM and MO results, where these coatings present denser morphology with lower number of superficial defect, as shown in Figs. 1 and 2. For low oxygen content films, the anodic branch of the potentiodynamic test shows similar kinetic, where the slope of the curves are similar between each other, indicating larger electrochemical activity of these films, likely due to the presence of a higher number of surface defects and more metallic Ta.

After 7 days of immersion the potenciodynamic curves evidence clear changes. All the samples present a more passive behavior compared to the curves immediately after immersion and a reduction of the current density, compared to the initial behavior. This indicates that after 7 days of immersion a passive layer is formed on the samples surface. Coatings with low content of oxygen still present the lowest corrosion resistance, attributed to a more metallic Ta composition of the films and subsequently higher number of defects. Thus, increasing the immersion time, the artificial saliva penetrates progressively throughout the porosity and the superficial defects, increasing the exposed area. The more columnar-like morphology and higher number of defects observed in the low oxygen content films accelerates the electrolyte intake, slowing down the reduction of the current density due to the fact that the exposed area is increasing, while on the other samples, a more compact morphology and less superficial defects help to block the electrolyte penetration.

In order to better understand the passivation of the surface, XPS studies were performed before and after 7 days of immersion (at OCP potential) to identify the chemical bonds present in the asdeposited coatings and after 7 days of immersion on artificial saliva at room temperature. XPS analysis was performed in two samples, Ta1 and TO6 since these two coatings presented the threshold values measured by EDS for the chemical composition, with highest Ta or O content, respectively.

It is important to note that, Ta element can assume different oxidation states as $\mathrm{Ta}^{5+}, \mathrm{Ta}^{4+}, \mathrm{Ta}^{2+}, \mathrm{Ta}^{+}$and $\mathrm{Ta}^{0}$ depending on the oxide type formed. Each oxidation state is characterized in Ta $4 \mathrm{f}$ spectra by a spin-orbital doublet (Ta 4 f $7 / 2$ and Ta 4 f $5 / 2$ ), frequently separated by $1.9 \mathrm{eV}$ [27]. The XPS results of Ta 1 and TO6 coatings, before and after immersion, are shown in Fig. 5.

Ta $4 \mathrm{f}$ photoemission spectrum at the films surface shows the spectral doublet around 26.3 (4f 7/2) and 28.2 (4f 5/2) eV for both analyzed coatings, before and after immersion. The binding energies of this doublet correspond to $\mathrm{Ta}_{2} \mathrm{O}_{5}$, indicating that the Ta atoms are positively charged in $\mathrm{Ta}^{5+}$ oxidation state relatively to Ta metal, due to the bonding of these atoms with oxygen [28]. This bond is confirmed by the $\mathrm{O} 1 \mathrm{~s}$ peak nearby $530.6 \mathrm{eV}$ that

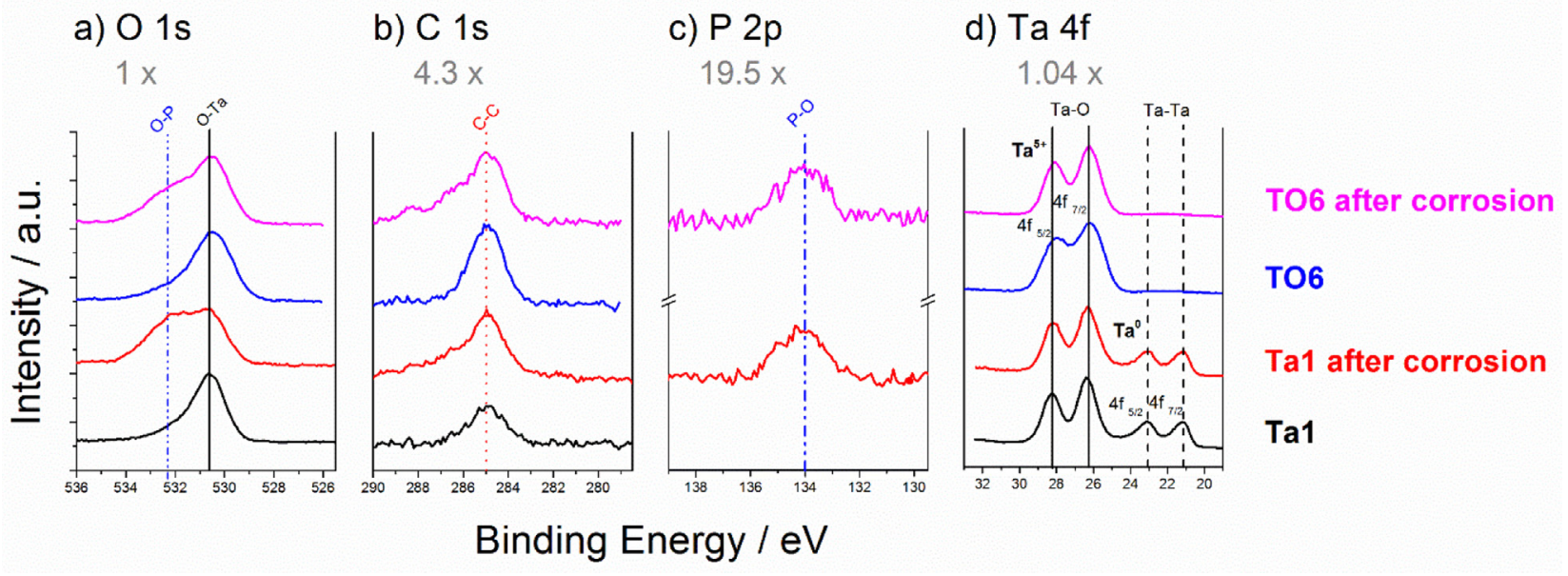

Fig. 5. XPS spectra of (a) O 1s, (b) C $1 \mathrm{~s}$, (c) P $2 \mathrm{p}$ and (d) Ta $4 \mathrm{f}$ of $\mathrm{Ta}_{1-\mathrm{x}} \mathrm{O}_{\mathrm{x}}$ coatings, before and after 7 days of immersion on artificial saliva at room temperature. 
a)

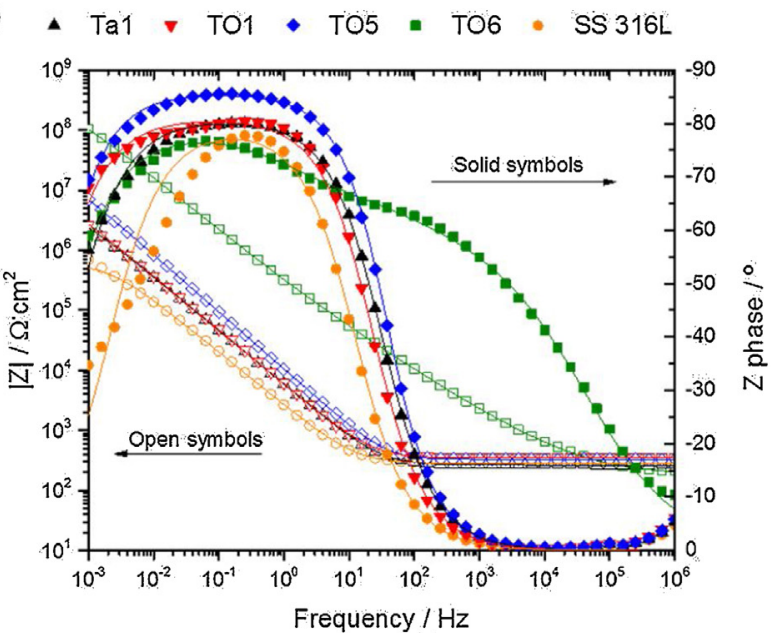

c)

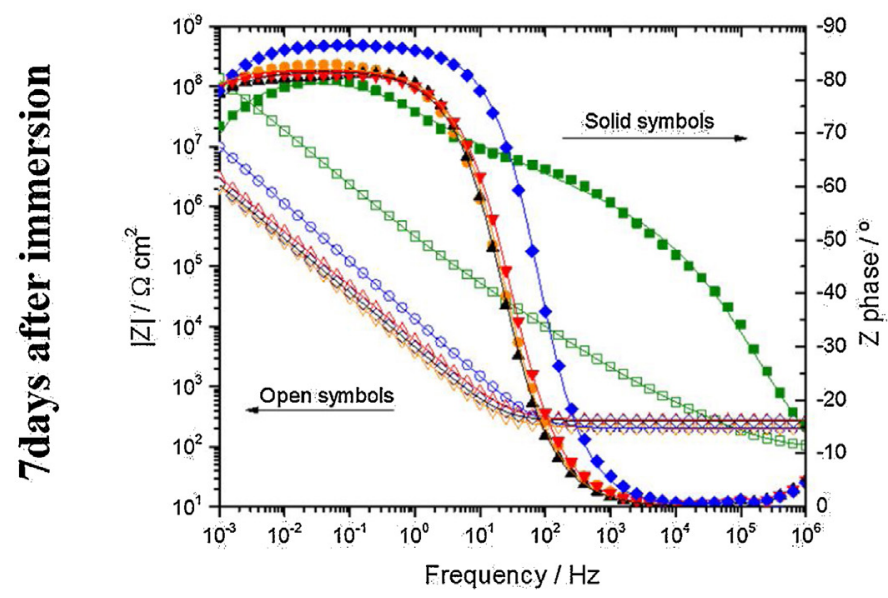

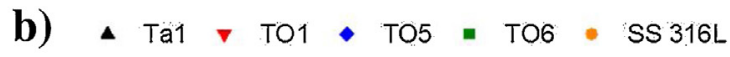

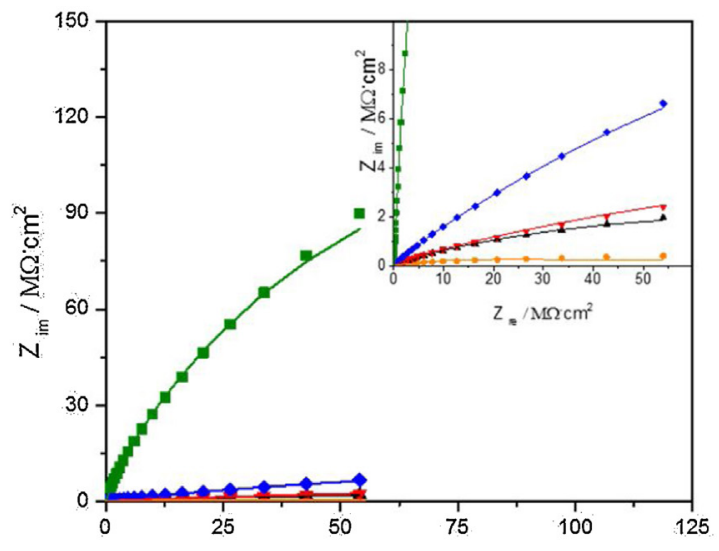

$\mathrm{Z}_{\mathrm{re}} / \mathrm{M} \Omega \mathrm{cm}^{2}$

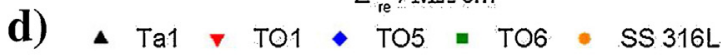

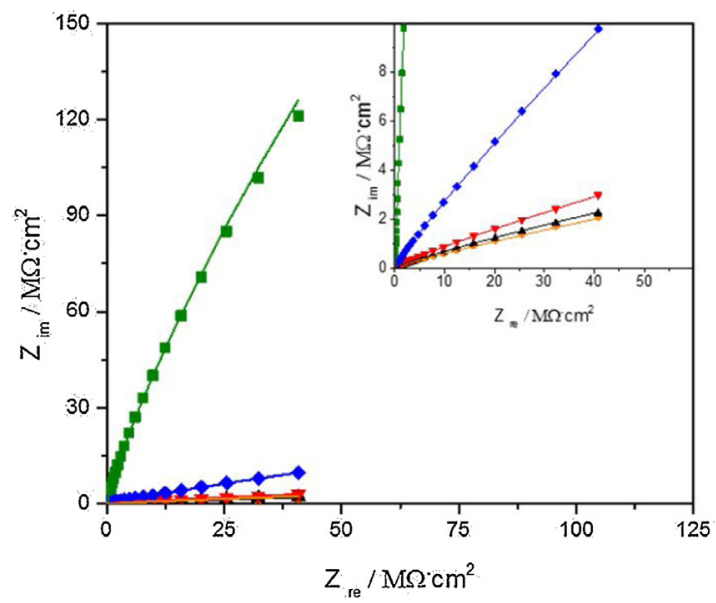

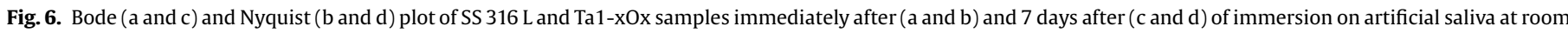

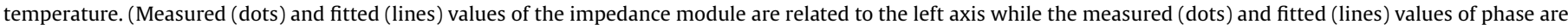
related to the right axis).

corresponds to the O-Ta chemical bonding (Fig. 5a), according with the literature [29]. The appearance of Ta $4 \mathrm{f}$ doublet assigned to $\mathrm{Ta}_{2} \mathrm{O}_{5}$ for as-deposited Ta1 coating demonstrates the high tendency of tantalum to passivate. Contrary to TO6, Ta1 displays an additional doublet around 21.1 and $23.0 \mathrm{eV}$, corresponding to the binding energies of $\mathrm{Ta}^{0}$, suggesting that the surface is composed by a mixture of pure metal and oxide. This mixture is likely to be due to a very thin passivation layer of $\mathrm{Ta}_{2} \mathrm{O}_{5}$ and the metallic state underneath the oxide. Hence, the more passive behavior of TO6 observe in the potentiodynamic tests can be attributed to a pure oxide composition on the surface of the coatings, while coatings with lower content of oxygen such Ta1 displays both tantalum oxide and metallic tantalum, exhibiting a more active electrochemical behavior.

It must be stressed that the growth of the oxide layer on Ta1 coatings was not observed, since the ratio between the $\mathrm{Ta}^{+5}$ and $\mathrm{Ta}^{0}$ before and after immersion is maintained, indicating that an additional parameter contributes to the passivation of the films and the corrosion protection. Such passivation is attributed to the formation of Ta-O-P layer, as seen in Fig. $5 c$. In effect, it has been reported that the phosphate ions can bind with metal oxides and form phosphates [30]. These phosphates ions are known as excellent inorganic corrosion inhibitors that provide protection to a surface susceptible to suffer corrosion $[31,32]$.
The small peak around $532.3 \mathrm{eV}$ in $\mathrm{O} 1 \mathrm{~s}$ spectrum of the immersed coatings is attributed to the surface passivation (O-P). It is important to note that the appearance of this minor peak is caused by the incorporation of a small amount of phosphorus in the top layer coating and can be confirmed by the P $2 p$ observed peak at $134.0 \mathrm{eV}$ that correspond to the P-O chemical bond [10], confirming the formation of a Ta-O-P passive layer.

Electrochemical impedance spectroscopy was performed to characterize in detail the corrosion performance of the samples. Fig. 6 shows the Bode and Nyquist plots for all the samples immediately after and 7 days after immersion.

The impedance results reveal larger impedance as oxygen increases in the films. This effect is clearly seen in the Nyquist plot shown in Fig. 6b and d, where the TO6 possesses the highest impedance values.

All the samples show a capacitive behavior with a single time constant, apart from the TO6 that displays a double time constant behavior, as shown in the phase angle curves present in Fig. 6a and c. A more capacitive-like behavior is observed as a function of the immersion time, seen in the increment of the imaginary part of the impedance and the phase at lower frequency values, as shown in Fig. 7. The increment indicates an enhanced protective behavior of the coatings, due to the passivation of the films, which increases 


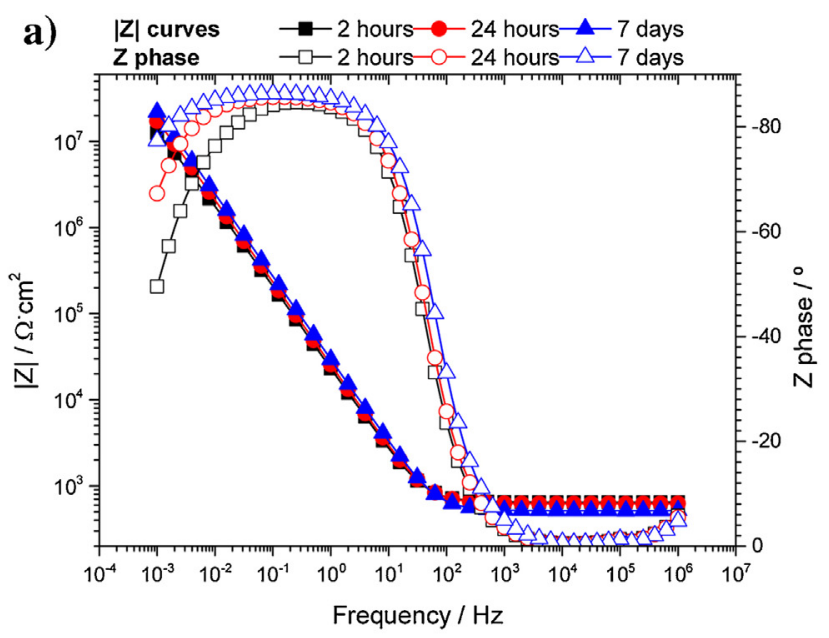

b)

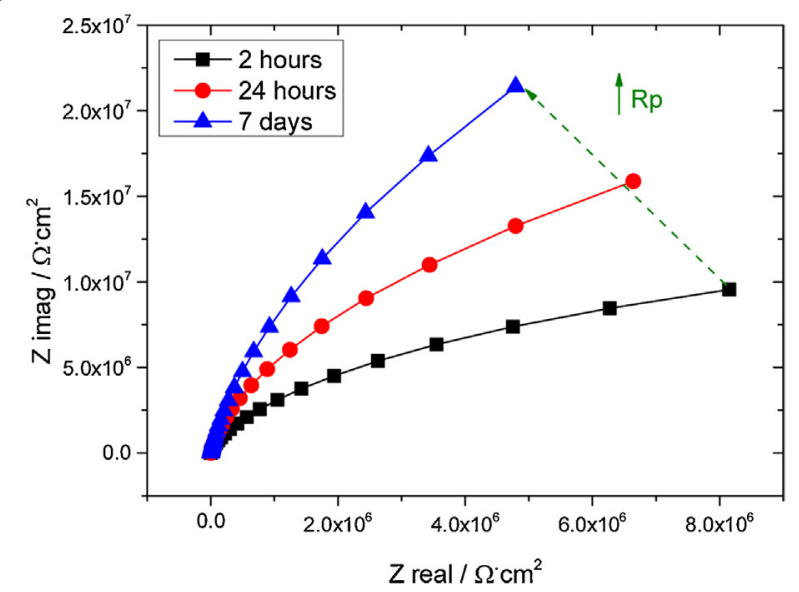

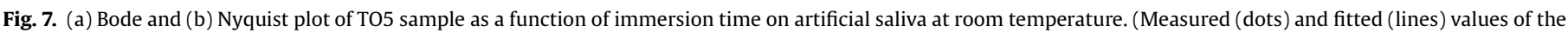
impedance module are related to the left axis while the measured (dots) and fitted (lines) values of phase are related to the right axis).

the charge transfer resistance of the coating during the corrosion process.

After 7 days of immersion, Ta 1 and TO1 films display a very similar electrochemical response, which mimics the SS 316L, as observed in Fig. 6c, where the impedance modulus and phase overlap among the three samples. This indicates that the open columnar morphology of these coatings allows the electrolyte to penetrate until the substrate, and thus, the electrochemical response is governed by the substrate. On the other hand, the

a)

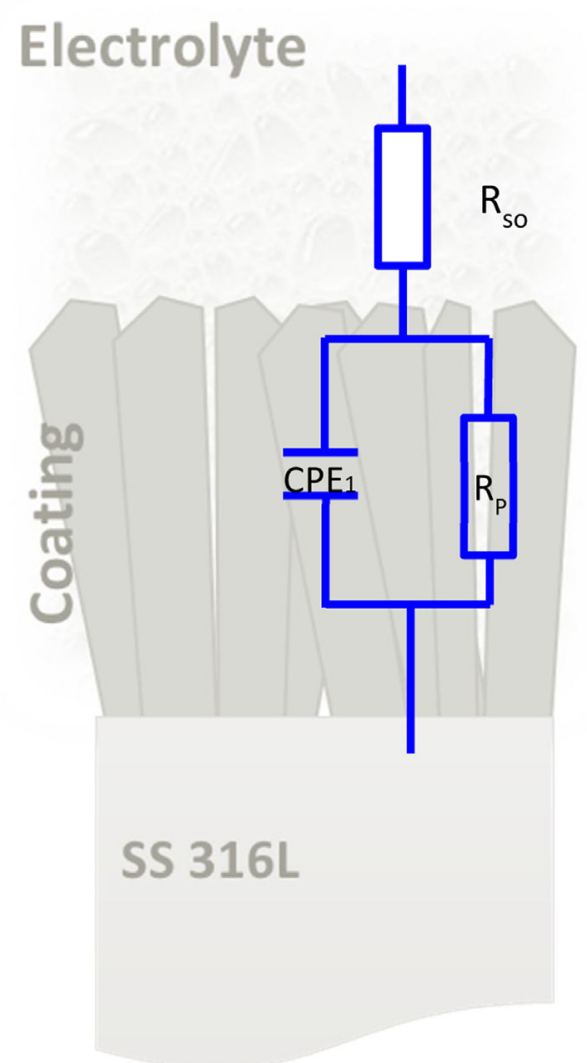

films with higher oxygen amount show a distinctive performance, enhancing the corrosion resistance of the substrate. TO5, for instance, possesses higher impedance, and phase values compared to the previously mentioned coatings, whereas TO6 shows a broader capacitive behavior and higher impedance values in the entire frequencies spectrum studied, indicating a more protective film.

In order to be able to quantify the electrochemical process, EIS results were fitted using two equivalent circuits (EC) shown in b)

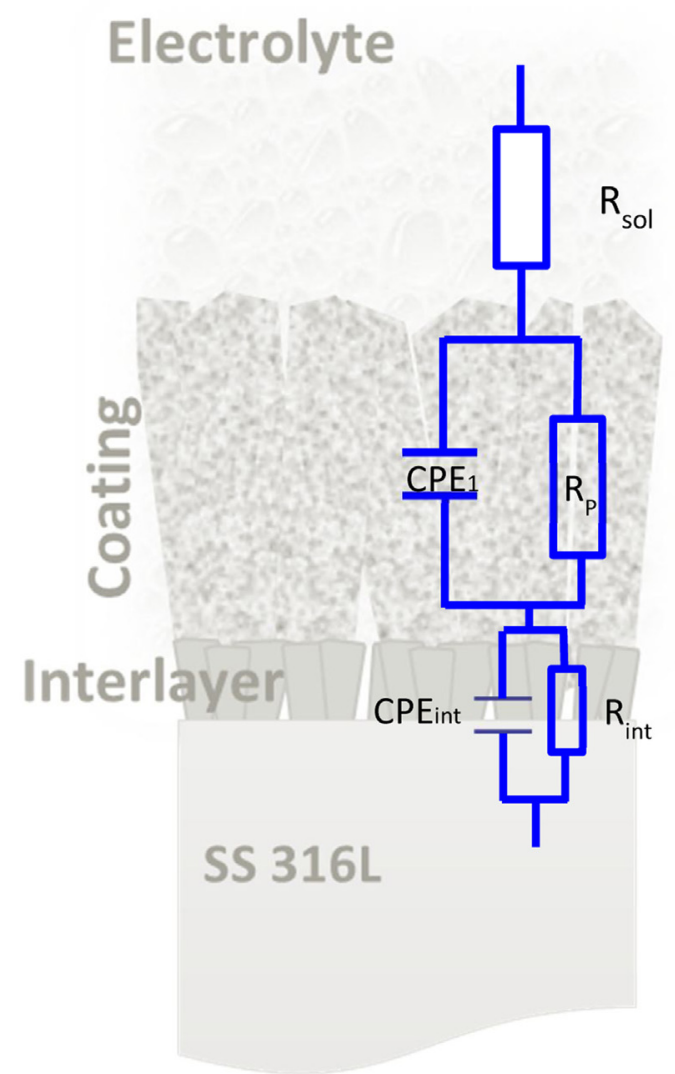

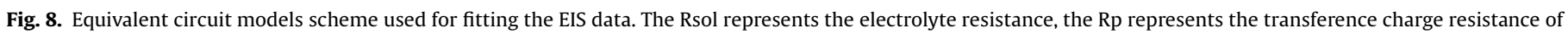
material and CPE represents the constant phase replacing a capacitance element. 


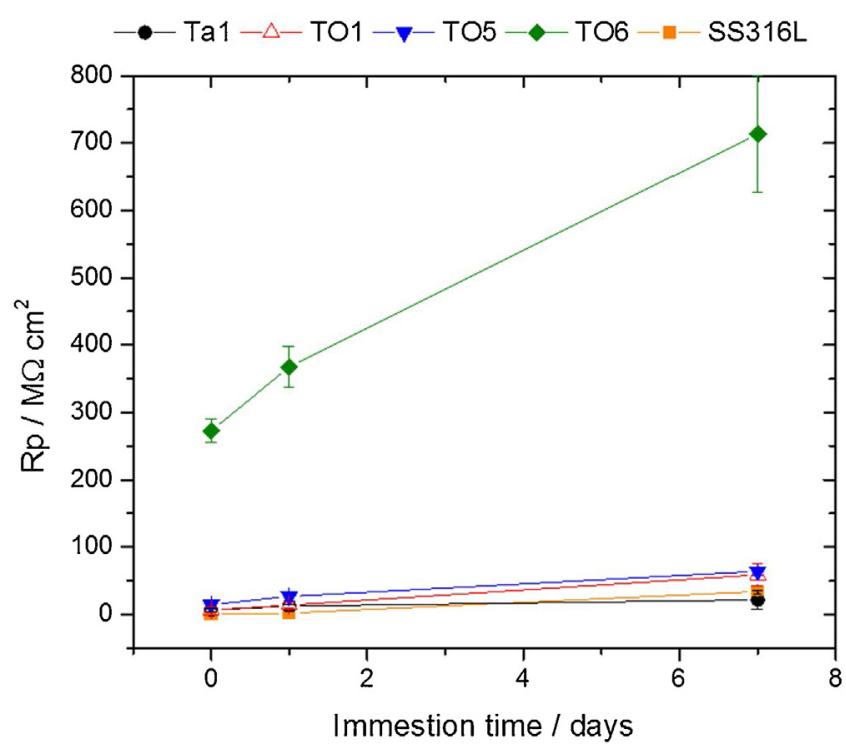

Fig. 9. Evolution of the polarization resistance of SS $316 \mathrm{~L}$ and Ta1-xOx coatings as a function of immersion time, on artificial saliva at room temperature.

Fig. 8. Fig. 8a represent the model used to fit SS 316L, Ta1, TO1 and TO5, where a constant phase element (CPE) is used to replace the capacitance element, to consider the surface roughness and heterogeneities. This element simulates the series combination of the double-layer and film capacitive behavior at the film/ electrolyte interface. The Rp, known as polarization resistance element, represents the charge transfer resistance. In the EC adopted for TO6, the first capacitive loop represents the tantalum oxide layer, while the second corresponds to the double-layer capacitance and charge transfer resistance at the interface between TO6 and the metallic portion (Ta and SS 316L), as described in Fig. 8b. It must be stressed that despite TO1 and TO5 coatings also possess a Ta interface, the absence of the electrochemical response of these layer may be due to the existence of metallic Ta in the functional layers, which hinder the differentiation between the coatings (TO1 and TO5), interlayer and substrate, and hence, a single time constant is observed in these samples (cf. Fig. 6c).

The evolution of the polarization resistance in the samples is plotted in Fig. 9, demonstrating a rise as a function of immersion time, validating once more the passivation of the surface. In addition, for TO6 the tendency may indicate obstruction of the diffusion path that contribute to the charge transfer in the system, due to passive film. For Ta1, TO1 and TO5 the consumption of free species, such as Ta, and hence its passivation also causes a slightly obstruction of the diffusion path in the coatings. However, the high number of surface defects in Ta1 and TO1 samples allows artificial saliva to progressively penetrate, explaining the similarities in the electrochemical response between these two samples and SS 316L.

For clarity, Table 2 only shows the fitting results of EIS data after 7 days of immersion.

The samples with higher oxygen content reveal a larger polarization resistance ( $\mathrm{Rp})$, in agreement with the potentiodynamic tests. T01 and TO5 show Rp values two or three folds higher than Ta1 and SS 316L samples, while TO6 has almost one order of magnitude difference. Once again the electrochemical response demonstrates that the stoichiometric oxide (T06 sample) exhibit a lower electrochemical activity in artificial saliva solution, due to the stability of the oxide phase in the film, whereas in substoichiometric oxides and Ta samples the metallic tantalum species contributes to anodic reaction while oxidizes, reducing the stability of the coatings.

Table 2

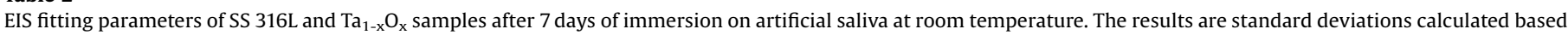
on experimental data of three separate samples.

\begin{tabular}{|c|c|c|c|c|c|c|c|c|}
\hline Sample & $\begin{array}{l}\mathrm{R}_{\mathrm{sol}} \\
\left(\Omega \mathrm{cm}^{2}\right)\end{array}$ & $\begin{array}{l}\mathrm{R}_{\mathrm{p}} \\
\left(\mathrm{M} \Omega \mathrm{cm}^{2}\right)\end{array}$ & $\begin{array}{l}\mathrm{Q} \\
\left(\mu \mathrm{S} \mathrm{s}^{\mathrm{n}} \mathrm{cm}^{-2}\right)\end{array}$ & $\mathrm{n}$ & $\begin{array}{l}\mathrm{C}_{\text {eff }} \\
\mu \mathrm{Fcm}^{-2}\end{array}$ & $\begin{array}{l}\mathrm{R}_{\text {pint }} \\
\left(\mathrm{k} \Omega \mathrm{cm}^{2}\right)\end{array}$ & $\begin{array}{l}\text { Q } \\
\left(\mu \mathrm{nt} s \alpha \mathrm{cm}^{-2}\right)\end{array}$ & $\mathrm{n}_{\text {int }}$ \\
\hline SS 316L & $169 \pm 50$ & $34.0 \pm 4.7$ & $40.4 \pm 12.8$ & $0.92 \pm 0.01$ & $78.5 \pm 30.7$ & - & - & - \\
\hline Ta1 & $209 \pm 75$ & $22.7 \pm 14.1$ & $24.0 \pm 21.1$ & $0.92 \pm 0.01$ & $70.6 \pm 21.8$ & - & - & - \\
\hline T01 & $257 \pm 45$ & $58.6 \pm 16.3$ & $40.3 \pm 8.43 .71$ & $0.89 \pm 0.01$ & $103.0 \pm 35.0$ & - & - & - \\
\hline T05 & $216 \pm 17$ & $64.0 \pm 6.5$ & $13.0 \pm 0.2$ & $0.96 \pm 0.00$ & $17.3 \pm 0.3$ & - & - & - \\
\hline T06 & $81 \pm 2$ & $714 \pm 87.0$ & $0.65 \pm 0.08$ & $0.89 \pm 0.00$ & $1.4 \pm 0.14$ & $73.5 \pm 17.9$ & $4.57 \pm 0.22$ & $0.56 \pm 0.00$ \\
\hline
\end{tabular}

All the models showed a goodness of fit between $3.2 \times 10^{-4}$ and $8.8 \times 10^{-4}$.

$$
\text { Capacitance }=\frac{\text { Matrial permittivity } * \text { exposed area }}{\text { oxide thickness }}
$$
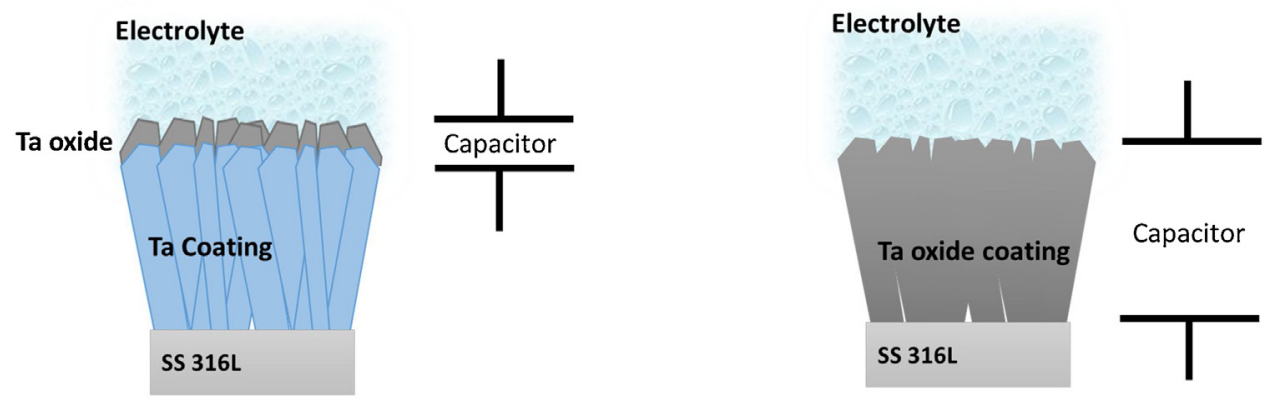

Oxygen content increases

Fig. 10. Schematic representation of the evolution of the capacitor as a function of oxygen content. 
Additionally, a progressive decrease of the Q parameter in the CPE compared to the control samples (SS 316L) is observed. Although this parameter does not directly represent the capacitance of the system, an effective capacitance may be calculated using the equation 1 [33].

$C_{e f f}=\frac{\left(Q \cdot R_{p}\right)^{\frac{1}{n}}}{R_{p}}$

Where $\mathbf{Q}$ and $\mathbf{n}$ are mathematical constants of the CPE impedance (for a pure capacitor elements $\mathbf{Q}=$ capacitance and $\mathbf{n}=1$ ) and $\mathbf{R}_{\mathbf{p}}$ is polarization resistance.

Table 2 shows a reduction of the effective capacitance of the system with the increase of the oxygen, due to a more ceramic behavior of the coatings, which reduces the formation of a double layer capacitance and reduces the overall capacitance due to the increase of the thickness in the dielectric materials (i.e. $\mathrm{Ta}_{2} \mathrm{O}_{5}$ ), as schematize in Fig. 10.

\section{Conclusions}

SEM, optical micrographs and XPS analysis have been combined with potenciodynamic and EIS electrochemical analysis aiming at investigate the corrosion/electrochemical stability and enhancement of the stainless steel 316L performance, provided by $\mathrm{Ta}_{1-\mathrm{x}} \mathrm{O}_{\mathrm{x}}$ coatings deposited by reactive magnetron sputtering. The assessment of sputtered Ta-based coatings revealed more compact coatings with morphology densification as oxygen amounts increase, showing smoother surfaces. Surface defects analysis revealed that the number of defects is reduced when oxygen is incorporated, attributed to denser coatings.

The electrochemical response evidenced a protective behavior of the films for polarization induced corrosion of SS 316L, matching the performance of the $\mathrm{CP} \mathrm{Ti} \mathrm{Gr} 2$, as well as a progressive increase in the corrosion resistance as a function of the immersion time in all the coatings, attributed to the passivation of the surface by both $\mathrm{Ta}_{2} \mathrm{O}_{5}$ and Ta-O-P formation. A more capacitive-like behavior is also observed as a function of the immersion time highlighting the enhanced protective behavior of the coatings.

\section{Acknowledgements}

This research is sponsored by FEDER funds through the program COMPETE - Programa Operacional Factores de Competitividade by national funds through FCT - Fundação para a Ciência e a Tecnologia -, in the framework of the Strategic Projects PEST-C/ FIS/UI607/2013, and PEst-C/EME/UI0285/2013, and with a PhD fellowship SFRH/BD/98199/2013.

The authors thank the financial support by IAPMEI funds through QREN - Implantes dentários inteligentes - SMARTDENT, Projeto Vale Inovação n. ${ }^{\circ}$ 2012/24005 and by MCTI/CNPQ $N^{\circ} 16 /$ 2012 TECNOLOGIAS INOVADORAS NA PRODUÇÃO,

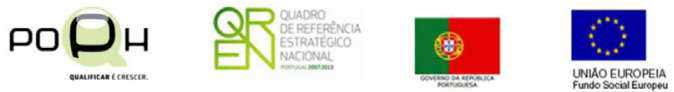

PROTOTIPAGEM E/OU AUMENTO DE ESCALA EM NANOTECNOLOGIA - Desenvolvimento de Titânio e Liga de Titânio Nanoestruturados com Tratamentos de Superfície para Aplicação em Implantes Ósseos.

\section{References}

[1] K. Subramani, R.T. Mathew, Chapter 6 - Titanium Surface Modification Techniques for Dental Implants-From Microscale to Nanoscale, in: K. Subramani, W. Ahmed (Eds.), Emerging Nanotechnologies in Dentistry, William Andrew Publishing, Boston, 2012, pp. 85-102.
[2] H. Rack, J. Qazi, Titanium alloys for biomedical applications, Materials Science and Engineering C 26 (2006) 1269-1277.

[3] J. Disegi, Titanium alloys for fracture fixation implants, Injury 31 (2000) D14D17.

[4] S.E. Kim, J.H. Lim, S.C. Lee, S.-C. Nam, H.-G. Kang, J. Choi, Anodically nanostructured titanium oxides for implant applications, Electrochimica Acta 53 (2008) 4846-4851.

[5] A. Maho, S. Linden, C. Arnould, S. Detriche, J. Delhalle, Z. Mekhalif, Tantalum oxide/carbon nanotubes composite coatings on titanium, and their functionalization with organophosphonic molecular films: A high quality scaffold for hydroxyapatite growth, Journal of Colloid and Interface Science 371 (2012) 150-158.

[6] M. Esposito, J. Hirsch, U. Lekholm, P. Thomsen, Biological factors contributing to failures of osseointegrated oral implants. (I) Sucess criteria and epidemiology, European Journal Oral Sciences 106 (1998) 527-551.

[7] V.K. Balla, S. Banerjee, S. Bose, A. Bandyopadhyay, Direct laser processing of a tantalum coating on titanium for bone replacement structures, Acta Biomaterialia 6 (2010) 2329-2334.

[8] C.J. Frandsen, K.S. Brammer, K. Noh, G. Johnston, S. Jin, Tantalum coating on TiO2 nanotubes induces superior rate of matrix mineralization and osteofunctionality in human osteoblasts, Materials Science and Engineering C 37 (2014) 332-341.

[9] B.R. Levine, S. Sporer, R.A. Poggie, C.J. Della Valle, J.J. Jacobs, Experimental and clinical performance of porous tantalum in orthopedic surgery, Biomaterials 27 (2006) 4671-4681.

[10] T. Miyazaki, H.-M. Kim, T. Kokubo, C. Ohtsuki, H. Kato, T. Nakamura, Mechanism of bonelike apatite formation on bioactive tantalum metal in a simulated body fluid, Biomaterials 23 (2002) 827-832.

[11] T. Kokubo, T. Matsushita, H. Takadama, T. Kizuki, Development of bioactive materials based on surface chemistry, Journal of the European Ceramic Society 29 (2009) 1267-1274.

[12] Y. Leng, J. Chen, P. Yang, H. Sun, J. Wang, N. Huang, The biocompatibility of the tantalum and tantalum oxide films synthesized by pulse metal vacuum arc source deposition Nuclear Instruments and Methods in Physics Research Section B: Beam Interactions with Materials and Atoms 242 (2006) 30-32.

[13] W. Yang, Y. Liu, Q. Zhang, Y. Leng, H. Zhou, P. Yang, J. Chen, N. Huang, Biomedical response of tantalum oxide films deposited by DC reactive unbalanced magnetron sputtering, Surface and Coatings Technology 201 (2007) 80628065.

[14] N. Wang, H. Li, J. Wang, S. Chen, Y. Ma, Z. Zhang, Study on the anticorrosion, biocompatibility, and osteoinductivity of tantalum decorated with tantalum oxide nanotube array films, ACS Applied Materials \& Interfaces 4 (2012) 45164523.

[15] C. Arnould, T. Korányi, J. Delhalle, Z. Mekhalif, Fabrication of tantalum oxide/ carbon nanotubes thin film composite on titanium substrate, Journal of colloid and Interface Science 344 (2010) 390-394.

[16] Y.-S. Sun, J.-H. Chang, H.-H. Huang, Corrosion resistance and biocompatibility of titanium surface coated with amorphous tantalum pentoxide, Thin Solid Films 528 (2013) 130-135.

[17] V.K. Balla, S. Bodhak, S. Bose, A. Bandyopadhyay, Porous tantalum structures for bone implants: fabrication, mechanical and in vitro biological properties, Acta Biomaterialia 6 (2010) 3349-3359.

[18] C.F. Almeida Alves, A. Cavaleiro, S. Carvalho, Bioactivity response of Ta1-xOx coatings deposited by reactive DC magnetron sputtering, Materials Science and Engineering C 58 (2016) 110-118.

[19] M. Mazur, M. Kalisz, D. Wojcieszak, M. Grobelny, P. Mazur, D. Kaczmarek, J. Domaradzki, Determination of structural, mechanical and corrosion properties of Nb2O5 and (NbyCu1-y)Ox thin films deposited on Ti6Al4V alloy substrates for dental implant applications, Materials Science and Engineering C 47 (2015) 211-221.

[20] J.C.M. Souza, S.L. Barbosa, E.A. Ariza, M. Henriques, W. Teughels, P. Ponthiaux, J.-P. Celis, L.A. Rocha, How do titanium and Ti6Al4V corrode in fluoridated medium as found in the oral cavity? An in vitro study, Materials Science and Engineering C 47 (2015) 384-393.

[21] S. Maeng, L. Axe, T. Tyson, P. Cote, Corrosion behaviour of electrodeposited and sputtered $\mathrm{Cr}$ coatings and sputtered Ta coatings with $\alpha$ and $\beta$ phases, Surface and Coatings Technology 200 (2006) 5767-5777.

[22] S. Maeng, L. Axe, T. Tyson, L. Gladczuk, M. Sosnowski, Corrosion behaviour of magnetron sputtered $\alpha$-and $\beta$-Ta coatings on AISI 4340 steel as a function of coating thickness, Corrosion science 48 (2006) 2154-2171.

[23] S.M. Maeng, L. Axe, T.A. Tyson, L. Gladczuk, M. Sosnowski, Corrosion behavior of magnetron sputtered $\alpha$-Ta coatings on smooth and rough steel substrates, Surface and Coatings Technology 200 (2006) 5717-5724.

[24] B. Díaz, J. Światowska, V. Maurice, A. Seyeux, E. Härkönen, M. Ritala, S. Tervakangas, J. Kolehmainen, P. Marcus, Tantalum oxide nanocoatings prepared by atomic layer and filtered cathodic arc deposition for corrosion protection of steel: Comparative surface and electrochemical analysis, Electrochimica Acta 90 (2013) 232-245.

[25] G. Xu, X. Shen, Y. Hu, P. Ma, K. Cai, Fabrication of tantalum oxide layers onto titanium substrates for improved corrosion resistance and cytocompatibility, Surface and Coatings Technology 272 (2015) 58-65.

[26] Y. Zhou, Z. Xie, H. Xiao, P. Hu, J. He, Effects of deposition parameters on tantalum films deposited by direct current magnetron sputtering, Vacuum 83 (2009) 286-291. 
[27] O. Kerrec, D. Devilliers, H. Groult, P. Marcus, Study of dry and electrogenerated Ta 205 and Ta/Ta 2 O 5/Pt structures by XPS, Materials Science and Engineering B 55 (1998) 134-142.

[28] Y. Masuda, S. Wakamatsu, K. Koumoto, Site-selective deposition and micropatterning of tantalum oxide thin films using a monolayer, Journal of the European Ceramic Society 24 (2004) 301-307.

[29] E. Atanassova, D. Spassov, X-ray photoelectron spectroscopy of thermal thin Ta 205 films on Si, Applied surface science 135 (1998) 71-82.

[30] M. Textor, L. Ruiz, R. Hofer, A. Rossi, K. Feldman, G. Hähner, N.D. Spencer, Structural Chemistry of Self-Assembled Monolayers of Octadecylphosphoric Acid on Tantalum Oxide Surfaces, Langmuir 16 (2000) 3257-3271.
[31] M.B. Valcarce, M. Vázquez, Phosphate ions used as green inhibitor against copper corrosion in tap water, Corrosion science 52 (2010) 1413-1420.

[32] L. Yohai, M. Vázquez, M.B. Valcarce, Phosphate ions as corrosion inhibitors for reinforcement steel in chloride-rich environments, Electrochimica Acta 102 (2013) 88-96.

[33] B. Hirschorn, M.E. Orazem, B. Tribollet, V. Vivier, I. Frateur, M. Musiani, Determination of effective capacitance and film thickness from constantphase-element parameters, Electrochimica Acta 55 (2010) 6218-6227. 